\title{
Corticosteroids for CAP, influenza and COVID-19: when, how and benefits or harm?
}

\author{
Ignacio Martin-Loeches (1) ${ }^{1,2,3,4,5}$ and Antoni Torres (10) $3,4,5$
}

Affiliations: ${ }^{1}$ Multidisciplinary Intensive Care Research Organization (MICRO), Dept of Intensive Care Medicine, St James's University Hospital, Dublin, Ireland. ${ }^{2}$ Trinity Centre for Health Sciences, Dublin, Ireland. ${ }^{3}$ Hospital Clinic, IDIBAPS, Universidad de Barcelona, Barcelona, Spain. ${ }^{4}$ Universitat de Barcelona, Barcelona, Spain. ${ }^{5}$ CIBERes, Barcelona, Spain.

Correspondence: Ignacio Martin-Loeches, Dept of Intensive Care Medicine, St James's Hospital, St James Street, Dublin 8, Ireland. E-mail: drmartinloechesđgmail.com

@ERSpublications

The recently published 2019 IDSA/ATS guidelines recommended the use of corticosteroids in the case of inpatients with septic shock refractory to vasopressors and fluid resuscitation https://bit.ly/39eXm 30

Cite this article as: Martin-Loeches I, Torres A. Corticosteroids for CAP, influenza and COVID-19: when, how and benefits or harm? Eur Respir Rev 2021; 30: 200346 [https://doi.org/10.1183/16000617.0346-2020].

\section{ABSTRACT}

Purpose: Corticosteroids have been considered in medicine for a long time, and they are broadly prescribed. In infectious diseases, corticosteroids have been regarded as a thread due to their immunosuppressive effects and therefore their anti-inflammatory properties.

Main: In recent years, there have been several studies published that aimed to determine the role of corticosteroids in patients with community-acquired pneumonia (CAP), because, despite significant advances in new antibiotics and supportive care, deaths of patients with CAP remain unacceptably high. While the 2007 Infectious Disease Society of America (IDSA)/American Thoracic Society (ATS) CAP guidelines did not mention the use of corticosteroids in the management of CAP, the recently published 2019 IDSA/ATS guidelines recommended their use in patients with septic shock refractory to vasopressors and fluid resuscitation. Regarding viral infection, the use of corticosteroids in patients with influenza has shown to be associated with significantly higher mortality and higher incidence of nosocomial infection, while in patients with coronavirus disease 2019 (COVID-19) there is a good body of evidence of the benefit of corticosteroids in terms of mortality.

Conclusions: The use of corticosteroids has been considered as a potential alternative co-adjuvant treatment in patients with pneumonia. In patients with COVID-19, the evidence is quite strong and there is a clear benefit of the use of corticosteroids in those patients presenting severe forms of disease.

\section{Introduction}

Corticosteroids are one of those drug groups that has been considered in medicine for a long time, and they are broadly prescribed. In infectious diseases, corticosteroids have been considered as a thread due to their immunosuppressive effects and therefore their anti-inflammatory properties. They have shown a benefit in only certain entities such as bacterial and tuberculosis meningitis, tetanus or pneumocystis pneumonia with moderate to severe hypoxaemia [1].

\section{Mechanism of action}

Since their discovery in 1940, corticosteroids have been used widely, mainly to control inflammation, in the management of autoimmune diseases, certain types of leukaemia and in immunosuppressive regimes

Provenance: Commissioned article, peer reviewed

Received: 28 Oct 2020 | Accepted: 22 Dec 2020

(C) The authors 2021 This version is distributed under the terms of the Creative Commons Attribution Non-Commercial Licence 4.0. For commercial reproduction rights and permissions contact permissions@ersnet.org 
following organ transplant. The inflammatory response of the host happens immediately after an infection as a primary defence mechanism in order to restore immune homeostasis with the elimination of the infectious agent and finally by tissue repair [2]. An experimental study showed that corticosteroids decrease lung inflammatory response and lung bacterial burden, confirming the results obtained through in vitro investigations [3]. Corticosteroids are deeply involved in the initial events of the inflammatory response, being involved in the resolution of inflammation. Corticosteroids can inhibit vasodilation, increase capillary permeability (humoral response) and leukocyte emigration into injured tissues (cellular response). Specifically, in high-dose glucocorticoid therapy there is an immediate risk of infection due to inhibitory effects on phagocytic cell function. The majority of immunosuppressive and anti-inflammatory actions of corticosteroids are related to the glucocorticoid receptor to inhibit the activity of key transcriptional regulators of pro-inflammatory genes, including NF- $\kappa \mathrm{B}$ in leukocytes. In addition, corticosteroids regulate the transcription of genes of pro-inflammatory effectors such as cytokines, chemokines and cell adhesion molecules that take part in the host inflammatory response. Downregulation of systemic inflammatory response in severe community-acquired pneumonia (CAP) patients may improve the clinical course, and may potentially decrease the development of acute respiratory distress syndrome (ARDS), sepsis and mortality in this population [4].

\section{Corticosteroids in CAP}

The use of corticosteroids has been very relevant in patients with acute respiratory failure defined by an arterial oxygen tension $\left(P_{\mathrm{aO}_{2}}\right)$ of $<8.0 \mathrm{kPa}(60 \mathrm{mmHg})$, an arterial carbon dioxide tension of $>6.0 \mathrm{kPa}$ $(45 \mathrm{mmHg})$, or both [5]. Patients with CAP can experience severe forms of disease associated with acute respiratory failure that require high concentration of supplementary oxygen, high-flow nasal cannula or invasive mechanical ventilation. In addition, CAP is a common cause of septic shock. In a recent randomised controlled trial (RCT) including patients with septic shock, up to 46\% of patients had CAP [6]. In recent years, several studies have been published that aimed to determine the role of corticosteroids in patients with CAP. Studies with corticosteroids in CAP are conducted because despite significant advances in new antibiotics and supportive care, the death of patients with CAP remains unacceptably high (14.7 per 100000 population as per Centers for Disease Control and Prevention). Pneumonia is the most common cause of infection-related mortality and is still one of the leading causes of death, not only in Western countries, but also in low- and middle-income countries [7, 8].

The use of corticosteroids in clinical trials of CAP as adjunct to antibiotics dates back 60 years. It is important to distinguish CAP from severe CAP. Defining severe CAP is a difficult task and the Infectious Disease Society of America (IDSA)/American Thoracic Society (ATS) CAP guidelines defined that either the need for invasive mechanical ventilation or direct admission to the intensive care unit (ICU) constitute major criteria for severe CAP [9]. While the 2007 IDSA/ATS CAP guidelines did not mention the use of corticosteroids the management of CAP [10], the recently published 2019 IDSA/ATS guidelines recommended their use in patients with septic shock refractory to vasopressors and fluid resuscitation [11]. One of the first hypothesis-generating trials for severe CAP was published in 2005, reporting the benefits of hydrocortisone in this subgroup of patients; however, concerns were high due to the small sample size and $0 \%$ mortality in the treatment arm [12]. After this study several systematic reviews and meta-analyses were published with very wide recommendations, from "no benefit of the use of corticosteroids in patients with CAP" [13] including its severe forms to "moderate-quality evidence" [14] and "limited data suggested that corticosteroid lowers mortality and shortens length of hospital stay for severe CAP” [15] (table 1).

Probably one of the game changers in the landscape of the clinical trials assessing the use of corticosteroids was the RCT published by TORRes et al. in 2015 [23]. In this study, patients with severe CAP were compared receiving either methylprednisolone $\left(0.5 \mathrm{mg} \cdot \mathrm{kg}^{-1}\right.$ twice daily over 5 days $)$ versus placebo. In this study only patients with severe CAP and a high inflammatory response (defined as a level of C-reactive protein $>150 \mathrm{mg} \cdot \mathrm{L}^{-1}$ at admission) were recruited. There was no difference in hospital mortality, but there was less treatment failure among patients from the methylprednisolone group, and therefore corticosteroid treatment reduced the risk of treatment failure (OR 0.34, 95\% CI 0.14-0.87; $\mathrm{p}=0.02$ ). A very large study was published in the same year by BLum et al. [24]. In this RCT, 785 patients hospitalised with CAP were randomised to receive oral prednisone $50 \mathrm{mg}$ or placebo once daily for 7 days. A shorter time to clinical stability was found with prednisone than with placebo (3.0 versus 4.4 days); however, there were no differences in mortality and significantly higher hyperglycaemia and insulin use in the corticosteroid group.

After this study, several meta-analyses were published, and particularly interesting are those conducted by Stern et al. [20], Briel et al. [21], Jiang et al. [22] and Huang et al. [25]. Stern et al. [20] conducted a systematic review and meta-analysis with the Cochrane Database in 2017, including 17 RCTs comprising a 
TABLE 1 Systematic review and meta-analysis for the use of corticosteroids in patients with community-acquired pneumonia (CAP)

\begin{tabular}{|c|c|c|c|c|}
\hline $\begin{array}{l}\text { Author, year } \\
\text { [reference] }\end{array}$ & Type of patient & Patients & RCTs & Findings \\
\hline SIEMPOS, 2008 [16] & $\begin{array}{l}\text { CAP with any severity (only } \\
\text { studies for severe CAP were } \\
\text { found) }\end{array}$ & 189 & 4 & $\begin{array}{l}\text { Limited data suggest that corticosteroid treatment lowers } \\
\text { mortality and shortens length of hospital stay for severe CAP }\end{array}$ \\
\hline SALLUH, 2010 [13] & Severe CAP & 415 & 3 & Do not recommend corticosteroids for severe CAP \\
\hline Chen, 2011 [17] & $\begin{array}{l}\text { Any type of pneumonia } \\
\text { including nosocomial and } \\
\text { child pneumonia }\end{array}$ & 437 & 6 & $\begin{array}{c}\text { Corticosteroids are generally beneficial for pneumonia } \\
\text { Evidence to make recommendation is lacking }\end{array}$ \\
\hline NiE, 2012 [18] & CAP with any severity & 1001 & 9 & $\begin{array}{l}\text { Corticosteroids are not recommended for CAP in general; } \\
\text { however, it is possible that corticosteroids lower mortality } \\
\text { from severe CAP and that corticosteroid treatment }>6 \text { days } \\
\text { may be more beneficial than } \leqslant 5 \text { days }\end{array}$ \\
\hline Cheng, 2014 [15] & Severe CAP & 264 & 4 & $\begin{array}{l}\text { Limited evidence suggests that corticosteroid treatment } \\
\text { lowers mortality from severe CAP }\end{array}$ \\
\hline Shafia, 2013 [14] & CAP requiring admission & 1119 & 8 & $\begin{array}{c}\text { Corticosteroids shorten length of hospital stay } \\
\text { Corticosteroids do not lower mortality }\end{array}$ \\
\hline HoRITA, 2015 [19] & CAP requiring admission & 1780 & 10 & $\begin{array}{c}\text { Corticosteroids shorten length of hospital stay for CAP } \\
\text { Corticosteroids shorten length to clinical stability for CAP } \\
\text { Corticosteroids lower mortality for CAP in ICU } \\
\text { Corticosteroids } \geqslant 6 \text { days is not more effective }\end{array}$ \\
\hline Stern, 2017 [20] & $\begin{array}{l}\text { Any type of pneumonia } \\
\text { including nosocomial and } \\
\text { child pneumonia }\end{array}$ & 2264 & 17 & $\begin{array}{l}\text { Corticosteroids reduced mortality and morbidity in adults } \\
\text { with severe CAP } \\
\text { Corticosteroids reduced morbidity, but not mortality, for } \\
\text { adults and children with nonsevere CAP } \\
\text { Corticosteroids were associated with more adverse events, } \\
\text { especially hyperglycaemia }\end{array}$ \\
\hline BRIEL, 2018 [21] & $\begin{array}{l}\text { CAP in Europe between } 2000 \\
\text { and } 2014\end{array}$ & $\begin{array}{l}1506 \text { (individual } \\
\text { data analysis) }\end{array}$ & 6 & $\begin{array}{c}\text { Corticosteroid treatment shortens time to clinical stability } \\
\text { and length of hospital stay } \\
\text { Corticosteroid treatment does not lower mortality } \\
\text { Corticosteroids increased risk for CAP-related } \\
\text { rehospitalisation and hyperglycaemia }\end{array}$ \\
\hline JIANG, 2019 [22] & Severe CAP & 665 & 10 & 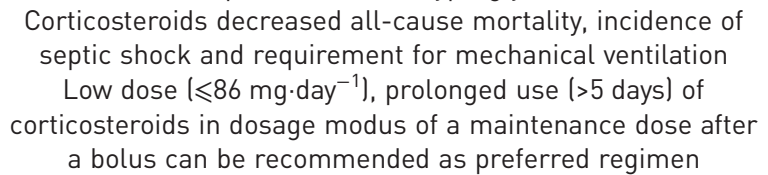 \\
\hline
\end{tabular}

Data are presented as n. RCT: randomised controlled trial; ICU: intensive care unit.

total of 2264 participants, and found that corticosteroids were shown to reduce mortality in adults with severe CAP, but were without significant benefit in nonsevere forms. In addition, this meta-analysis found that early clinical failure rates were significantly reduced with corticosteroids in people with severe and nonsevere pneumonia and that corticosteroids reduced time to clinical cure, length of hospital and ICU stays and development of respiratory failure or shock not present at pneumonia onset. Interestingly, none of the adult trials included in this publication restricted the inclusion to either bacterial or virus aetiology, and none reported relevant outcome data by pathogen. This might have important implications, as the inflammatory response and the radiographic presentation caused by bacterial pneumonia can be different from that caused by a virus. This finding has been reported only in children [26]. The systematic review and meta-analysis conducted in 2018 by BRIEL et al. [21] was very interesting, as it included individual patient data. The authors included 1506 individual patients in six trials and there was no difference in 30 -day all-cause mortality, considering that the mortality was quite low (5.0\% versus $5.9 \%$ deaths in the corticosteroid groups and in placebo groups, respectively). The most intriguing finding was that the use of adjunct corticosteroids reduced time to clinical stability and length of hospital stay by 1 day, but with an increased risk for CAP-related rehospitalisation and hyperglycaemia. Finally, in 2019 JIANG et al. [22] found that low dose ( $\leqslant 86 \mathrm{mg}$ of prednisone) and prolonged ( $>5$ days) use of corticosteroids in a dosage modus of a maintenance dose after a bolus obtained better results in death through subgroup analysis. Regarding the type of corticosteroids, HuANG et al. [25] found that prednisolone or methylprednisolone therapy reduced total mortality, whereas hydrocortisone did not. 
A final and important point is that the use of macrolides has been reported to improve survival in patients with severe CAP $[27,28]$. It is well known that the immunomodulatory effect of macrolides and the combination of macrolides and corticosteroids might have a summative effect. There are not many studies published based on this hypothesis, but СЕССАТо et al. [29] performed a post hoc exploratory analysis of patients included in an RCT with the use of corticosteroids. The authors did not find significant differences in treatment failure (early or late), or in-hospital mortality after adjusting for severity confounding factors including severity, time and centre of enrolment.

\section{Role of viruses in CAP}

In adults, viral causes of CAP are poorly characterised. A landmark study by JENNINGs et al. [30] used an extensive array of viral diagnostic tests in adult patients admitted with CAP over a 1-year period. The authors found that a virus was isolated in one-third of the cases, with rhinoviruses and influenza A being the most common. In a recent systematic review on the aetiology of CAP [31], it was found that the incidence of bacterial CAP has declined; however, Streptococcus pneumoniae remains the most common cause of CAP. The reason for this decline is probably because a more systematic routine diagnostic of PCR for viruses is currently conducted. In summary, this meta-analysis reported that viruses were reported on average in $\sim 10 \%$ of cases, but recent PCR-based studies could isolate a respiratory virus in $\sim 30 \%$ of cases of CAP, with substantial rates of viral/bacterial co-infection. There are no data available regarding the use of corticosteroids in patients with CAP and respiratory viruses, but the question arises whether the use of corticosteroids could be beneficial in viral CAP, especially in pandemic situations? In the following sections, we discuss the role of corticosteroids in both influenza and severe acute respiratory syndrome coronavirus 2 (SARS-CoV-2).

\section{Corticosteroids in influenza}

Influenza-related severe pneumonia and ARDS are severe clinical presentations in patients with influenza. Due to high morbidity and mortality, corticosteroids were seen as potential co-adjuvants in patients with influenza, especially those with the most severe forms. Animal studies suggested that the use of corticosteroids could ameliorate lung lesion in infected mice and improved survival induced by influenza A (H1N1pdm09) virus [32]. Due to this potential mechanism, the use of steroids has been seen as a potential alternative to stop disease progression and improve clinical outcomes.

The first multicentric observational study was published in 2011 under the European Society of Intensive Care Medicine H1N1 registry. It included 220 patients in ICUs around the globe. One of the most surprising findings was that the use of corticosteroids was as high as $60 \%$ and the use of corticosteroids was found not to be improving ICU mortality and was associated with increased risk of hospital-acquired pneumonia [33]. After this study, others were published showing the same results in patients with influenza A (H1N1pdm09) in Korea [34], France [35] and Canada [36] and with influenza A (H7N9) viral pneumonia in China [37]. After these studies, there was a good body of evidence against the routine use of steroids in patients with influenza. More recently, a large cohort study of critically ill patients admitted to ICUs in Spain found that the use of steroids was still prevalent and being prescribed in approximately one-third of the patients admitted to the 148 ICUs in the study. The relevance of this observational study is that it found that the use of corticosteroids was associated to an increased ICU mortality by a propensity score matching and competing risks analysis [38].

Several meta-analyses were published after the aforementioned observational studies. One of the largest meta-analyses included 10 trials involving 6548 patients with influenza pneumonia [39]. The authors found that mortality was higher in patients who received corticosteroids (risk ratio (RR) $1.75,95 \%$ CI $1.30-2.36$, $\mathrm{z}=3.71 ; \mathrm{p}=0.0002$ ), and similar results were observed in the subgroup analysis of patients with H1N1 (RR 1.69, 95\% CI 1.15-2.47, $\mathrm{z}=2.68 ; \mathrm{p}=0.007$ ). Corticosteroids had no effect on mechanical ventilation days, patients had a longer ICU length of stay, and rate of secondary infection was higher than in the patients who did not receive corticosteroids. In addition, a recent a meta-analysis [40], included patients without restrictions on influenza subtype, patient age or study setting and with the severity as inclusion criterion: ARDS $\left(P_{\mathrm{aO}_{2}}\right.$ /inspiratory oxygen fraction ratio $<300 \mathrm{mmHg}$ ) and severe pneumonia. A total of 15 studies (6427 patients) were included in the meta-analysis, and similarly to the previous study, corticosteroid therapy was associated with significantly higher mortality and a three times higher incidence of nosocomial infection.

\section{Corticosteroids in coronavirus disease 2019}

The SARS-CoV-2 outbreak has overwhelmed healthcare systems worldwide. Patients often present with cough and fever that progresses to acute respiratory failure and ARDS with refractory hypoxaemia [41, 42]. ARDS has been found to be the primary cause of death in coronavirus disease 2019 (COVID-19) [43], and $5-10 \%$ of the patients had bacterial/fungal co-infection during hospital admission depending on antibiotic use $[44,45]$. Since December 2019, there have been 40.9 million confirmed cases of COVID-19 (up to 
October 30, 2020), and 1.3 million deaths worldwide have been reported [46]. The clinical course of COVID-19 remains to be fully investigated, with new data available that describe the disease pathogenesis; however, no specific pharmacological therapies have been proven effective.

The pathological mechanism of the virus is through the invasion of epithelial and alveolar cells that trigger an immune response in different cells including monocytes, T-cells, B-cells and natural killer cells that eventually release cytokines and chemokines. Locally, there is a massive migration of inflammatory cells into the lungs and an excessive immune response can provoke a further damage to the lung [47]. Autopsy studies have found that T-cells are hyperactivated with elevation of Th17, and high cytotoxicity of CD8 T-cells may account for the severe immune injury [48]. Blocking the release of cytokines and the suppression and deficiency of T-cell immunity may be the main potential mechanisms of treatment of severe COVID-19 that can be enhanced by the use of corticosteroids.

At the beginning of the pandemic, the efficacy and safety of corticosteroid therapy in COVID-19 was unclear. Because of previous findings of delayed clearance of viral RNA from the respiratory tract with corticosteroids in Middle East respiratory syndrome [49] and in the blood in severe acute respiratory syndrome (SARS) [50], the Surviving Sepsis Campaign recommended against the routine use of systemic corticosteroids in mechanically ventilated adults with COVID-19 and respiratory failure [51]. The majority of the publications were single-centre retrospective studies $[52,53]$. Corticosteroids were given to one out of five patients. Some authors reported good clinical outcomes with the use of steroids in terms of clinical symptoms and oxygenation [54], reduced lengths of hospitalisation and ICU stay [55] and decreased risk of death for individuals with COVID-19 with ARDS [56]; however, in the majority of patients included in these early trials, the mortality rate in the corticosteroid group was higher than in the noncorticosteroid group and patients with severe disease were reported to have received more corticosteroids than in those with nonsevere disease [47].

The RECOVERY (Randomised Evaluation of COVID-19 Therapy) trial's first pre-print was published on June 22, 2020 [57] as a preliminary report assessing the use of dexamethasone in hospitalised patients with COVID-19 [58]. More than 6000 patients were recruited (2104 patients were assigned to receive dexamethasone) and the use of dexamethasone resulted in lower 28-day mortality among those presenting a more severe disease manifested by receiving either invasive mechanical ventilation or oxygen alone. No differences were observed among those receiving no respiratory support. However, this study did not analyse laboratory values, viral load, etc., it had an open-label design and included all types of patients (critically and not critically ill) with a substantially high mortality rate $(>20 \%$ in both arms including non-critically-ill patients is extremely high). After this study, two RCTs were published. The REMAP-CAP trial [59] was a randomised, embedded, multifactorial adaptive platform and open-label trial conducted in patients with severe COVID-19 following admission to an ICU for respiratory or cardiovascular organ support at 121 sites in eight countries. The study found that a treatment of hydrocortisone (with a 7-day fixed-dose course or shock-dependent dosing) resulted in a higher probability of superiority with regard to the odds of improvement in organ-support-free days within 21 days ( $93 \%$ and $80 \%$, respectively). In this study neither hydrocortisone of the groups met the pre-specified criteria for statistical superiority and thus definitive conclusions cannot be drawn. The CAPE COVID trial [60] was performed in France with low-dose hydrocortisone, stopped early after 149 patients (probably underpowered) and could not find any benefit of corticosteroids in reducing treatment failure (death or persistent respiratory failure). Finally, the last big trial was the CoDEX trial [61] conducted in Brazil in patients with moderate or severe ARDS (according to the Berlin definition) and COVID-19. It included almost 300 patients and the conclusions were that the use of dexamethasone resulted in a statistically significant increase in the number of ventilator-free days (days alive and free of mechanical ventilation) over 28 days. After these trials, a systematic review and meta-analysis was conducted by the World Health Organization Rapid Evidence Appraisal for COVID-19 Therapies (REACT) working group [62]. This was a prospective meta-analysis that pooled data from seven RCTs that evaluated the efficacy of corticosteroids in 1703 critically ill patients with COVID-19 (dexamethasone, hydrocortisone or methylprednisolone (678 patients) or usual care or placebo (1025 patients)). Not surprisingly, based on the RCTs discussed, the meta-analysis found that administration of systemic corticosteroids, compared with usual care or placebo, was associated with lower 28-day all-cause mortality. The overall fixed-effect odds ratio was 0.61 (95\% CI 0.48-0.78; $<<0.001$ ) for trials with low doses of corticosteroids, while the fixed-effect odds ratio was 0.83 (95\% CI $0.53-1.29$; $\mathrm{p}=0.46$ ) for trials with high doses of corticosteroids; however, the comparison of association between low and high doses was imprecisely estimated. Another important finding was the same effect for mortality with either dexamethasone or hydrocortisone.

\section{Corticosteroids and nosocomial infections}

One of the common threats when administering corticosteroids is the possibility of the development nosocomial infections. In general, the nosocomial infections reported in patients with influenza are 
bacterial ones. In two of the observational studies [63, 64], Acinetobacter baumannii was isolated in almost one-third of the cases, while in another study including almost 2000 patients S. pneumoniae accounted for half of the cases, followed by Pseudomonas aeruginosa (10.1\%) and Staphylococcus aureus (7.5\%) [38].

Apart from bacterial infection, one of the most severe complications is probably the development of invasive fungal infections such as invasive pulmonary aspergillosis (IPA). Aspergillus fumigatus has been reported in patients with influenza, in some cases named influenza-associated invasive pulmonary aspergillosis (IAPA). In an observational study of 645 patients admitted with influenza A (H1N1pdm09), S. pneumoniae was identified as the most prevalent bacteria in $>50 \%$ of cases; however, the presence of Aspergillus was seen in 10 (8.8\%) patients ( $\mathrm{n}=2$ definitive, $\mathrm{n}=6$ probable and $\mathrm{n}=2$ unproven) [65]. More recently, the same authors followed patients for a period of 7 years and the incidence of Aspergillus remained similar (7.5\%) [66].

A landmark study was published by a Dutch-Belgian consortium in 2018 [67]. The authors conducted a retrospective multicentre cohort study and found that IPA was diagnosed in two out of 10 patients admitted with influenza. Besides influenza, the administration of corticosteroids was also found to be a risk factor for IPA (adjusted OR 1.59, 95\% CI 1.30-1.99; $\mathrm{p}<0.0001$ ). To the best of our knowledge, in severe CAP, there have been no reports of invasive fungal infection with the concomitant use of corticosteroids.

In coronaviruses, there have been some reports of fatal aspergillosis in patients with SARS who died of aspergillosis after prolonged treatment with corticosteroids [68]. More recently, in patients with 2019 novel coronavirus, there are reports of COVID-19-associated pulmonary aspergillosis (CAPA). Some case series have been published, such as VAN ARKEL et al. [69] which reported an incidence of 19.4\% CAPA out of 31 mechanically ventilated patients. Three patients received corticosteroids before ICU admission and no other immunosuppressive medication was given before CAPA diagnosis. In a larger study, WHITE et al. [70] conducted a national, multicentre, prospective cohort evaluation of an enhanced testing strategy to diagnose invasive fungal disease in COVID-19 intensive care patients. They included 135 patients and CAPA was diagnosed in $14.1 \%$ of cases, with a trend of the use of corticosteroids and history of chronic respiratory disease as independent risk factors that increased the likelihood of CAPA. A major concern arises with the trials favouring the use of corticosteroids; it is likely that corticosteroids will be used more often and the development of CAPA might increase. We recommend the use of clear algorithms including galactomannan antigens and 1,3- $\beta$-D-glucan circulating in serum and bronchoalveolar lavage for the diagnosis of IPA [71].

\section{Conclusions}

The use of corticosteroids has been considered as a potential alternative co-adjuvant treatment in patients with pneumonia. Timing is important and corticosteroids when indicated should be started as soon as possible (within the first $24 \mathrm{~h}$ ). Type and duration differ depending on the clinical identity of disease (table 2). The recently published IDSA/ATS guidelines do not recommend corticosteroid treatment of CAP, except in the case of comorbid conditions, such as COPD, asthma or an autoimmune disease [11]. The recommendation is aligned with the Surviving Sepsis Campaign guidelines [72] that recommend the use of hydrocortisone in patients who have CAP with septic shock that is refractory to fluid resuscitation and vasopressor support, with a weak recommendation and low quality of evidence. In patients with influenza, corticosteroids have shown no benefit, as published by multiple observational studies and with

TABLE 2 Corticosteroids in community-acquired pneumonia (CAP) versus coronavirus disease-2019 (COVID-19)

CAP

IDSA/ATS severe CAP [11]

First $24 \mathrm{~h}$

Prednisone (50 mg daily)

Methylprednisolone (40-80 mg daily)

Dexamethasone (5 mg daily)

$5-8$ days

Outcome

Harms
Decrease treatment failure and mortality

Increased readmission in one study
COVID-19

IDSA: Infectious Diseases Society of America; ATS: American Thoracic Society; CAPA: COVID-19-associated pulmonary aspergillosis. " : as defined in the RECOVERY trial [58]. 
the increased risk of complications such as IAPA. In patients with COVID-19, the evidence is quite strong and there is a clear benefit to the use of corticosteroids in those patients presenting severe forms of disease. However, the appearance of cases with CAPA and the widespread use of corticosteroids is a matter of concern and further studies need to be conducted to determine whether there is an association.

In summary, there is still a mixed effect of corticosteroids for CAP and probably some benefit against treatment failure in severe forms of pneumonia with an increased inflammatory response; they are not recommended for influenza and strongly recommended for COVID-19.

Conflict of interest: None declared.

\section{References}

1 McGee S, Hirschmann J. Use of corticosteroids in treating infectious diseases. Arch Intern Med 2008; 168: 1034-1046.

2 Vandewalle J, Luypaert A, De Bosscher K, et al. Therapeutic mechanisms of glucocorticoids. Trends Endocrinol Metab 2018; 29: 42-54.

3 Sibila O, Agustí C, Torres A, et al. Experimental Pseudomonas aeruginosa pneumonia: evaluation of the associated inflammatory response. Eur Respir J 2007; 30: 1167-1172.

4 Coutinho AE, Chapman KE. The anti-inflammatory and immunosuppressive effects of glucocorticoids, recent developments and mechanistic insights. Mol Cell Endocrinol 2011; 335: 2-13.

5 Roussos C, Koutsoukou A. Respiratory failure. Eur Respir J 2003; 22: Suppl. 47, 3s-14s.

6 Annane D, Renault A, Brun-Buisson C, et al. Hydrocortisone plus fludrocortisone for adults with septic shock. N Engl J Med 2018; 378: 809-818.

7 Kegler SR, Baldwin GT, Rudd RA, et al. Increases in United States life expectancy through reductions in injury-related death. Popul Health Metr 2017; 15: 32.

8 Centers for Disease Control and Prevention. National Center for Health Statistics. Pneumonia. www.cdc.gov/nchs/ fastats/pneumonia.htm Date last accessed: December 10, 2020. Date last updated: October 30, 2020.

9 Mandell LA. Severe community-acquired pneumonia (CAP) and the Infectious Diseases Society of America/ American Thoracic Society CAP guidelines prediction rule: validated or not. Clin Infect Dis 2009; 48: 386-388.

10 Mandell LA, Wunderink RG, Anzueto A, et al. Infectious Diseases Society of America/American Thoracic Society consensus guidelines on the management of community-acquired pneumonia in adults. Clin Infect Dis 2007; 44: Suppl. 2, S27-S72.

11 Metlay JP, Waterer GW, Long AC, et al. Diagnosis and treatment of adults with community-acquired pneumonia. An official clinical practice guideline of the American Thoracic Society and Infectious Diseases Society of America. Am J Respir Crit Care Med 2019; 200: e45-e67.

12 Confalonieri M, Urbino R, Potena A, et al. Hydrocortisone infusion for severe community-acquired pneumonia: a preliminary randomized study. Am J Respir Crit Care Med 2005; 171: 242-248.

13 Salluh JIF, Shinotsuka CR, Soares M, et al. Cortisol levels and adrenal response in severe community-acquired pneumonia: a systematic review of the literature. J Crit Care 2010; 25: 541.e1-541.e8.

14 Shafiq M, Mansoor MS, Khan AA, et al. Adjuvant steroid therapy in community-acquired pneumonia: a systematic review and meta-analysis. J Hosp Med 2013; 8: 68-75.

15 Cheng M, Pan ZY, Yang J, et al. Corticosteroid therapy for severe community-acquired pneumonia: a meta-analysis. Respir Care 2014; 59: 557-563.

16 Siempos II, Vardakas KZ, Kopterides P, et al. Adjunctive therapies for community-acquired pneumonia: a systematic review. J Antimicrob Chemother 2008; 62: 661-668.

17 Chen Y, Li K, Pu H, et al. Corticosteroids for pneumonia. Cochrane Database Syst Rev 2011; 3: CD007720.

18 Nie W, Zhang Y, Cheng J, et al. Corticosteroids in the treatment of community-acquired pneumonia in adults: a meta-analysis. PLoS One 2012; 7: e47926.

19 Horita N, Otsuka T, Haranaga S, et al. Adjunctive systemic corticosteroids for hospitalized community-acquired pneumonia: systematic review and meta-analysis 2015 update. Sci Rep 2015; 5: 14061.

20 Stern A, Skalsky K, Avni T, et al. Corticosteroids for pneumonia. Cochrane Database Syst Rev 2017; 12: CD007720.

21 Briel M, Spoorenberg SMC, Snijders D, et al. Corticosteroids in patients hospitalized with community-acquired pneumonia: systematic review and individual patient data metaanalysis. Clin Infect Dis 2018; 66: 346-354.

22 Jiang $\mathrm{S}$, Liu T, Hu Y, et al. Efficacy and safety of glucocorticoids in the treatment of severe community-acquired pneumonia: a meta-analysis. Medicine 2019; 98: e16239.

23 Torres A, Sibila O, Ferrer M, et al. Effect of corticosteroids on treatment failure among hospitalized patients with severe community-acquired pneumonia and high inflammatory response: a randomized clinical trial. JAMA 2015; 313: $677-686$.

24 Blum CA, Nigro N, Briel M, et al. Adjunct prednisone therapy for patients with community-acquired pneumonia: a multicentre, double-blind, randomised, placebo-controlled trial. Lancet 2015; 385: 1511-1518.

25 Huang J, Guo J, Li H, et al. Efficacy and safety of adjunctive corticosteroids therapy for patients with severe community-acquired pneumonia. Medicine 2019; 98: e14636.

26 Virkki R, Juven T, Rikalainen $\mathrm{H}$, et al. Differentiation of bacterial and viral pneumonia in children. Thorax 2002; 57: 438-441.

27 Martin-Loeches I, Lisboa T, Rodriguez A, et al. Combination antibiotic therapy with macrolides improves survival in intubated patients with community-acquired pneumonia. Intensive Care Med 2010; 36: 612-620.

28 Martin-Loeches I. Why macrolides? Jpn J Antibiot 2014; 68: Suppl. A, 56.

29 Ceccato A, Cilloniz C, Ranzani OT, et al. Treatment with macrolides and glucocorticosteroids in severe community-acquired pneumonia: a post-hoc exploratory analysis of a randomized controlled trial. PLoS One 2017; 12: $\mathrm{e} 0178022$.

30 Jennings LC, Anderson TP, Beynon KA, et al. Incidence and characteristics of viral community-acquired pneumonia in adults. Thorax 2008; 63: 42-48. 
31 Shoar S, Musher DM. Etiology of community-acquired pneumonia in adults: a systematic review. Pneumonia 2020; 12: 11 .

32 Li C, Yang P, Zhang Y, et al. Corticosteroid treatment ameliorates acute lung injury induced by 2009 swine origin influenza A (H1N1) virus in mice. PLoS One 2012; 7: e44110.

33 Martin-Loeches I, Lisboa T, Rhodes A, et al. Use of early corticosteroid therapy on ICU admission in patients affected by severe pandemic $(\mathrm{H} 1 \mathrm{N1}) \mathrm{v}$ influenza A infection. Intensive Care Med 2011; 37: 272-283.

34 Kim S-H, Hong S-B, Yun S-C, et al. Corticosteroid treatment in critically ill patients with pandemic influenza A/ H1N1 2009 infection. Am J Respir Crit Care Med 2011; 183: 1207-1214.

35 Brun-Buisson C, Richard J-CM, Mercat A, et al. Early corticosteroids in severe influenza A/H1N1 pneumonia and acute respiratory distress syndrome. Am J Respir Crit Care Med 2011; 183: 1200-1206.

36 Delaney JW, Pinto R, Long J, et al. The influence of corticosteroid treatment on the outcome of influenza A (H1N1pdm09)-related critical illness. Crit Care 2016; 20: 75.

37 Cao B, Gao H, Zhou B, et al. Adjuvant corticosteroid treatment in adults with influenza A (H7N9) viral pneumonia. Crit Care Med 2016; 44: e318-e328.

38 Moreno G, Rodríguez A, Reyes LF, et al. Corticosteroid treatment in critically ill patients with severe influenza pneumonia: a propensity score matching study. Intensive Care Med 2018; 44: 1470-1482.

39 Ni YN, Chen G, Sun J, et al. The effect of corticosteroids on mortality of patients with influenza pneumonia: a systematic review and meta-analysis. Crit Care 2019; 23: 99.

40 Zhou Y, Fu X, Liu X, et al. Use of corticosteroids in influenza-associated acute respiratory distress syndrome and severe pneumonia: a systemic review and meta-analysis. Sci Rep 2020; 10: 3044.

41 Wu Z, McGoogan JM. Characteristics of and important lessons from the coronavirus disease 2019 (COVID-19) outbreak in China: summary of a report of 72314 cases from the Chinese Center for Disease Control and Prevention. JAMA 2020; 323: 1239-1242.

42 Ge H, Wang X, Yuan X, et al. The epidemiology and clinical information about COVID-19. Eur J Clin Microbiol Infect Dis 2020; 39: 1011-1019.

43 Verity R, Okell LC, Dorigatti I, et al. Estimates of the severity of coronavirus disease 2019: a model-based analysis. Lancet Infect Dis 2020; 20: 669-677.

44 COVID-ICU Group on behalf of the REVA Network and the COVID-ICU Investigators. Clinical characteristics and day-90 outcomes of 4244 critically ill adults with COVID-19: a prospective cohort study. Intensive Care Med 2021; 47: 60-73.

45 Rawson TM, Moore LSP, Zhu N, et al. Bacterial and fungal coinfection in individuals with coronavirus: a rapid review to support COVID-19 antimicrobial prescribing. Clin Infect Dis 2020; 71: 2459-2468.

46 World Health Organization (WHO). WHO Coronavirus Disease (COVID-19) Dashboard. http://covid19.who.int Date last accessed: December 10, 2020.

47 Yang J-W, Yang L, Luo R-G, et al. Corticosteroid administration for viral pneumonia: COVID-19 and beyond. Clin Microbiol Infect 2020; 26: 1171-1177.

$48 \mathrm{Xu} \mathrm{Z}$, Shi L, Wang Y, et al. Pathological findings of COVID-19 associated with acute respiratory distress syndrome. Lancet Respir Med 2020; 8: 420-422.

49 Arabi YM, Mandourah Y, Al-Hameed F, et al. Corticosteroid therapy for critically ill patients with Middle East respiratory syndrome. Am J Respir Crit Care Med 2018; 197: 757-767.

50 Lee N, Allen Chan KC, Hui DS, et al. Effects of early corticosteroid treatment on plasma SARS-associated coronavirus RNA concentrations in adult patients. J Clin Virol 2004; 31: 304-309.

51 Alhazzani W, Møller MH, Arabi YM, et al. Surviving Sepsis Campaign: guidelines on the management of critically ill adults with coronavirus disease 2019 (COVID-19). Intensive Care Med 2020; 46: 854-887.

52 Huang C, Wang Y, Li X, et al. Clinical features of patients infected with 2019 novel coronavirus in Wuhan, China. Lancet 2020; 395: 497-506.

53 Wang $\mathrm{D}, \mathrm{Hu}$ B, Hu C, et al. Clinical characteristics of 138 hospitalized patients with 2019 novel coronavirus-infected pneumonia in Wuhan, China. JAMA 2020; 323: 1061-1069.

54 Zhou W, Liu Y, Tian D, et al. Potential benefits of precise corticosteroids therapy for severe 2019-nCoV pneumonia. Signal Transduct Target Ther 2020; 5: 18.

55 Wang Y, Jiang W, He Q, et al. A retrospective cohort study of methylprednisolone therapy in severe patients with COVID-19 pneumonia. Signal Transduct Target Ther 2020; 5: 57.

56 Wu C, Chen X, Cai Y, et al. Risk factors associated with acute respiratory distress syndrome and death in patients with coronavirus disease 2019 pneumonia in Wuhan, China. JAMA Intern Med 2020; 180: 934-943.

57 Horby P, Mafham M, Linsell L, et al. Effect of hydroxychloroquine in hospitalized patients with COVID-19: preliminary results from a multi-centre, randomized, controlled trial. medRxiv 2020; preprint [https://doi.org/10. $1101 / 2020.07 .15 .20151852]$.

58 RECOVERY Collaborative Group, Horby P, Lim WS, et al. Dexamethasone in hospitalized patients with covid-19 - preliminary report. N Engl J Med 2020; in press [https://doi.org/10.1056/NEJMoa2021436].

59 Angus DC, Derde L, Al-Beidh F, et al. Effect of hydrocortisone on mortality and organ support in patients with severe COVID-19: the REMAP-CAP COVID-19 corticosteroid domain randomized clinical trial. JAMA 2020; 324: 1317-1329.

60 Dequin P-F, Heming N, Meziani F, et al. Effect of hydrocortisone on 21-day mortality or respiratory support among critically ill patients with COVID-19: a randomized clinical trial. JAMA 2020; 324: 1298-1306.

61 Tomazini BM, Maia IS, Cavalcanti AB, et al. Effect of dexamethasone on days alive and ventilator-free in patients with moderate or severe acute respiratory distress syndrome and COVID-19: the CoDEX randomized clinical trial. JAMA 2020; 324: 1307-1316.

62 Sterne JAC, Murthy S, Diaz JV, et al. Association between administration of systemic corticosteroids and mortality among critically ill patients with COVID-19: a meta-analysis. JAMA 2020; 324: 1330-1341.

63 Huang S-F, Fung C-P, Perng D-W, et al. Effects of corticosteroid and neuraminidase inhibitors on survival in patients with respiratory distress induced by influenza virus. J Microbiol Immunol Infect 2017; 50: 586-594.

$64 \mathrm{Li} \mathrm{H}$, Yang S, Gu L, et al. Effect of low-to-moderate-dose corticosteroids on mortality of hospitalized adolescents and adults with influenza A(H1N1)pdm09 viral pneumonia. Influenza Other Respir Viruses 2017; 11: 345-354. 
65 Martín-Loeches I, Sanchez-Corral A, Diaz E, et al. Community-acquired respiratory coinfection in critically ill patients with pandemic 2009 influenza A(H1N1) virus. Chest 2011; 139: 555-562.

66 Martin-Loeches I, Schultz MJ, Vincent J-L, et al. Increased incidence of co-infection in critically ill patients with influenza. Intensive Care Med 2017; 43: 48-58.

67 Schauwvlieghe AFAD, Rijnders BJA, Philips N, et al. Invasive aspergillosis in patients admitted to the intensive care unit with severe influenza: a retrospective cohort study. Lancet Respir Med 2018; 6: 782-792.

68 Wang H, Ding Y, Li X, et al. Fatal aspergillosis in a patient with SARS who was treated with corticosteroids. N Engl J Med 2003; 349: 507-508.

69 van Arkel ALE, Rijpstra TA, Belderbos HNA, et al. COVID-19-associated pulmonary aspergillosis. Am J Respir Crit Care Med 2020; 202: 132-135.

70 White PL, Dhillon R, Cordey A, et al. A national strategy to diagnose coronavirus disease 2019-associated invasive fungal disease in the intensive care unit. Clin Infect Dis 2020; in press [https://doi.org/10.1093/cid/ciaa1298].

71 Torres A, Martin-Loeches I. Invasive pulmonary aspergillosis in ventilator-associated pneumonia: the hidden enemy? Am J Respir Crit Care Med 2020; 202: 1071-1073.

72 Rhodes A, Evans LE, Alhazzani W, et al. Surviving Sepsis Campaign: international guidelines for management of sepsis and septic shock: 2016. Intensive Care Med 2017; 43: 304-377. 